\title{
Un Humanista Moderno
}

ocos espectáculos ofrece la naturaleza humana más hermosos que la cima excelsa y serena de una existencia iluminada por la razón y la sabiduría. No me propongo tejer una vez más el elogio retórico de la vejez, ilustrado por tantas sentencias famosas, ni robarle argumentos a Cicerón y a todos aquéllos que después de él, o antes, asumieron la defensa del anciano que sabe llevar la carga de los años con dignidad. Un solo ejemplo vivo vale más que un discurso. Y ejemplo magnífico es para mí el que encarna Baldomero Sanín Cano contemplando el mundo con mirada lúcida y corazón firme desde la cumbre de sus ochenta y siete años. Ejemplo cuya dimensión crece cuando esa sabia vejez corona una existencia de pensamiento y estudio, admirable por su precocidad y fecundidad.

Cuando en la Buenos Aires anterior a 1890, abierta sobre el Atlántico, los escritores argentinos más curiosos de novedades tenían por principal y casi exclusiva fuente de cultura la francesa, salvo alguna rara y vaga excursión hecha a los demás hontanares europeos, en Bogotá, aislada en la meseta colombiana, Sanín Cano, aunque adicto conocedor deí pensamiento y el arte franceses, les descubría a sus amigos los secretos de las literaturas germánicas y nórdicas contemporáneas, y en ellas a agitadores espirituales de la talla de Federico Nietzsche, Jorge Brandes y Enrique Ibsen.

iY qué amigos los suyos, los que recibieron el impulso de su inquietud intelectual, los que compartieron su constante anhelo de renovarse mediante la lectura! Baste recordar, sin adjetivos superfluos, a José Asunción Silva y Guillermo Valencia, además de poetas, insaciables de conocimientos. Otro de los iniciados fué Víctor M. Londoño, cuya vida celebró Sanín Cano con nobles palabras 
socráticas, cuando el talentoso poeta, crítico y ensayista falleció en 1936.

Desde aquellos lejanos días finiseculares, Sanín Cano ha sido a través de seis decenios el maestro que da sin tasa, liberalmente, la palabra esclarecedora y orientadora; $y$ lo ha hecho como quien sembrara sin que le preocupe negociar los frutos en monedas de reputación y vanidad.

Cuando llegó a Buenós Aires en 1925 en calidad de ministro plenipotenciario, no teníamos noticias de ningún libro suyo, y sin embargo, los argentinos cultos lo diputábamos maestro por su obra de ensayista dispersa en revistas y diarios. En el discurso con que lo saludé en el banquete que le ofreció la revista Nosotros, expliqué nuestra admiración por su obra, a la que definí, sin mengua para ella, de periodística. Pido disculpa de repetir algunos párrafos de ese discurso, pues no sabría caracterizar de modo diferente su obra total. Dije entonces entre otras cosas que hoy omito:

"Hijo de América, no teméis la democracia ni la libertad. Podéis condenar, habéis condenado sus errores y parodias, pero nunca renegaríais de ellas. Los valores caducos de Europa, sus extravíos presentes, no os alucinan ni seducen. Siempre fuisteis un severo censor del militarismo, de la diplomacia enredista, de los turbios manejos financieros, de la venalidad de la prensa, de la concupiscencia, inmoralidad, frivolidad y anarquía de esta sociedad decadente. De estirpe hispana, manejáis con perfecta maestría nuestro idioma, por el que el nombre y el espíritu de España sobrenadarán sobre la corriente de los siglos. Vuestra cultura es aquélla, universal, que sólo son capaces de atesorar con juvenil avidez, sin exclusivismos, los espíritus esclarecidos de América cuando dirigen sus miradas hacia el saber del viejo mundo. Singularmente modesto, habéis dejado dispersa en los periódicos vuestra múltiple y riquísima labor, con la cual podrían y deberán formarse muchos libros orgánicos, sólidos, henchidos de ideas, noblemente inspirados y sabrosamente escritos. iQué exquisita cultura se muestra en ellos y aun en la más pasajera expresión de vuestro pensamiento! A través de los años, antes de que colaborarais en La Nación y después que os incorporasteis al cuerpo de sus corresponsales, nos habéis hablado de política, de economía, de historia, de ciencia, de arte, de letras, siempre con criterio seguro de hombre que ha acrisolado su cultura y madurado 
su pensamiento. Vuestros artículos, vuestros ensayos, son de una pieza: dicen bellamente, con vigor y rigor lógico cosas nobles y justas. La larga residencia en Inglaterra ciertamente no ha sido ajena a vuestro perfeccionamiento espiritual. Tan español como sois por la lengua rica y jugosa que manejáis, tenéis mucho de inglés por la seriedad y solidez del raciocinio. En vuestros escritos nunca asoman la garrulería, el conceptismo, el preciosismo que tantos estragos hacen hasta entre los más agudos ingenios españoles. Aquella digna seriedad del pensamiento que tanto debe a las disciplinas clásicas, que se muestra en los publicistas ingleses, así llámense Macaulay como escriban en los periódicos del día, seriedad que no está reñida con un sano humorismo, no es el rasgo menos característico y precioso de vuestra obra. $\mathrm{Y}$ como habéis contemplado durante muchos años las cosas del mundo desde un alto observatorio europeo (aludia a su colaboración en la revista Hispania dirigida en Londres por Santiago Pérez Triana), apartado de las mezquindades de localismo y desligado de los intereses creados, y sois independiente y tolerante por naturaleza, no hay impulso ni movimiento modernos, aunque encontrados, en esta época de todas las tentativas y todas las experiencias, que no hayáis considerado con comprensiva atención. ¿Qué más se necesita para hacer un maestro? Talento, ilustración, carácter, clarividencia, afán de bien, todo lo tenéis."

Al fin se decidió Sanín Cano en Buenos Aires, ante la insistencia de los amigos, a recopilar ese mismo año una corta serie de sus ensayos en el volumen titulado La civilización manual, al que luego han seguido otros no menos sustanciosos. "Soy un periodista, nada más que un periodista" - nos dijo él la noche ya recordada, bromeando ingeniosamente sobre su carencia de aquellas facultades que hacen a los poetas, a los novelistas, a los dramaturgos y a los filósofos especulativos. Un periodista, sin duda; un gran periodista del linaje ilustre que cuenta en su seno eminentes pensadores de todos los tiempos, aun antes de la invención de las gacetas; una de esas plumas clarificadoras y disociadoras de ideas, expertas en convertir lo accidental y episódico en permanente, la anécdota en categoría. Por algo él ha hecho el elogio del valor documental de la anécdota elevada a símbolo. Ameno y oportuno narrador de cuentos al caso, lo mismo en sus artículos que en los convivios, siempre sabe extraer de aquéllos una filosofía general de la vida. 
La pluma del grande anciano conserva en la vejez la misma agilidad de su mente, tan despierta hoy como en la mocedad. Si bien no me llegan todos los comentarios de los sucesos actuales que él publica con asiduidad extraordinaria en El Tiempo de Bogotá, los pocos que me es dado leer, ya directamente, ya reproducidos en otros periódicos, me atestiguan aquella misma alacridad strya. Más aún, nos admira verle mantener incólumes los ideales qué encendían el ánimo de la juventud americana a fines del siglo xIx, sin las claudicaciones, renunciamientos y entregas que trae la edad o impone la necesidad. Siempre es digno de respeto el que se mantiene firme como una roca contra el embate mudable de los tiempos; como quiera que sea no renovarse en sentido progresivo revela estrechez cerebral. Ahora bien, cuando en los ancianos hay mudanza, ésta generalmente es en sentido regresivo, desandando el camino, abjurando los ideales de la juventud, naturalmente más amplios, cálidos, generosos y audaces que los de la edad cana. El joven "pertenece al partido de los que buscan la verdad sin temor de encontrarla y de los que no envenenan las certidumbres grandes con dudas pequeñas" - diré adaptando al caso una fórmula de ingenieros. Esa juventud del espíritu ha mantenido siempre Sanín Cano. Buena escuela fué aquella en que aguzó la inteligencia forjando sus poderosas armas críticas y dialécticas: capaz de arremeter sin miedo contra todos los ídolos, mitos y supersticiones de la tribu y de la plaza, así como de sostener denodadamente los principios sustanciales que son la sal de la vida $\mathrm{y}$ que la hacen merecedora de vivirse, abandonados uno a uno $\mathrm{y}$ poco por este siglo de voluntaria servidumbre.

Ello no le ha impedido al maestro colombiano revisar sus juicios ante el curso de los hechos sociales de que ha sido espectador durante largos decenios, practicando un fecundo escepticismo en el cual sonríe un templado humorismo de cepa sajona. Tal actitud crítica le ha sido posible porque su mente se ha abierto curiosa a todas las ideas. Tratando de su ilustre compatriota Miguel Antonio Caro, "hombre de convicciones profundas e invariables", "cuyas opiniones en religión, en literatura, en filosofía apenas se modificaron en los cuarenta o más años de su actividad política y literaria" - deja caer por ahí esta sentencia entre las muchas que realzan con observaciones de carácter general su reciente revista (1944) de las letras colombianas, editada en la colección mexicana Tierra Firme: "En 
materias de arte y de literatura comprender mucho es más segura táctica que proscribir demasiado." Por cierto la censura implícita en la sentencia no puede aplicársele a él, ni en arte, ni en literatura, ni en ningún otro orden del pensamiento. Al revés de Caro que "negó muchas cosas", Sanín Cano ha procurado entender cuantas más ha podido, sin exceptuar la frecuente locura y estulticia humanas, que le han inspirado más conmiseración irónica y filosófica tristeza que indignación y odio. Su escepticismo activo y fecundo es el de aquella generación renaniana que dudó de muchas cosas, pero nunca de la necesidad de encaminarse por la comprensión de todas, a la tolerancia y la indulgencia.

La citada historia literaria, no por sencilla y sin pretensiones, desprovista de médula, es espejo de la ecuanimidad de su mente. No puedo menos de señalar en ella la reserva discreta con que el ilustre octogenario, formado intelectualmente entré la generación clasicista, que en su patria reaccionó contra el romanticismo, y la modernista, trata la poesía surrealista que hoy ocupa el tablado, absteniéndose de condenar lo que tan distante está sin duda de sus gustos y criterios estéticos.

De todos sus juicios resuma el concepto que él tiene de la vida y el hombre; en ellos se trasparenta cuáles son las normas ideales de la conducta ética e intelectual que, al aspirar a hacerlas suyas, configuran su personalidad. En estos rasgos de Pedro Henríquez Ureña, tan verdaderos, trazados por Sanín Cano ¿cómo no reconocer al pintor a la vez que al modelo, los que tuvimos la dicha de tratar personalmente a los dos? "Tenía el don de gentes -dijo del amigo cuando murió- y de él aprendíamos cosas de valor sus amigos, fuera de las aulas, en su conversación jugosa, plácida y llena de atractivos."

No ha trazado nunca Sanín Cano la semblanza de otro en prólogos, cartas y artículos, sin proyectar involuntariamente en el papel los rasgos bellísimos de su propio ser íntimo. ¿No se retratará en cierto aspecto a si mismo, sin proponérselo, cuando refiriéndose a José Eusebio Caro, el padre de Miguel Antonio, estampa el siguiente juicio? "Hay temperamentos de agitadores en el buen sentido de la palabra, cerebros que excitan la actividad de otras inteligencias y promueven el adelantamiento de las letras y a veces su decadencia. La palabra hablada de un hombre versado en historia de 
las literaturas, el buen gusto de quien no escribe pero difunde sus opiniones en la conversación diaria, en los cenáculos, por medio de conferencias, suelen tener a veces más importancia que el ejemplo ofrecido en composiciones literarias propias o en trabajos de crítica dados a luz en la prensa."

Eso ha sido y es Sanín Cano: un agitador, un excitador de otras inteligencias, un animador, un guía espiritual, y entendiéndolo así América le rinde por la voz de hombres de distintas naciones el homenaje de su gratitud y admiración. Ha merecido ese homenaje el infatigable sembrador que, sin prevalerse, para descansar, de los derechos que otorga la edad, ha arrojado a manos llenas ideas estimulantes en artículos, ensayos y conferencias, los cuales también por la pulcritud formal hacen de él un maestro de la literatura periodística. Por la universalidad de su mente conviénele asimismo con justicia el título de humanista moderno, en una nación que ha dado al habla castellana tres o cuatro figuras eminentes de humanistas de cultura clásica.

Roberto F. Giusti 